\title{
Responsible regulation: prudence, precaution and stewardship
}

\author{
ROGER BROWNSWORD*
}

King's College London

\section{Introduction}

Tn Rights, Regulation and the Technological Revolution, ${ }^{1}$ I identified a number of generic challenges that regulators face as they endeavour to put in place the right kind of environment for the development, application and exploitation of emerging technologies a regulatory environment that is properly geared for risk management and benefit sharing, that is both legitimate and effective, and that is fully connected to its technological targets. In the present paper, I draw out more explicitly three elements of this initial overview, namely: the idea of a "regulatory environment", the challenge of "regulatory prudence", and the scope and function of regulatory "stewardship" (together with its link to precautionary reasoning).

First, revisiting my idea of a regulatory environment, I highlight the three key registers in which regulators signal their directions. These comprise: two normative registers, the moral and the prudential, in which regulatees are directed as to how they ought to act if they are to do the right thing relative to, respectively, other-regarding criteria and the criterion of selfinterest; and, a non-normative register, where the signal to regulatees is that certain acts are simply not a practical option (indeed, in some instances, performance of these acts is, quite literally impossible). The relevance of these registers and the significance of regulators relying on one register rather than another will become apparent in my discussion of stewardship.

Secondly, I identify regulatory prudence as a distinctive challenge. Essentially, the idea is that regulators (acting as proxies for their regulatees) have a prudential responsibility to ensure that, wherever there is reason to suppose that risks to health, safety and environment might be presented by new technologies, then such risks are expertly assessed and

* Professor of Law, King's College London, and Honorary Professor in Law at the University of Sheffield. Earlier versions of this paper were given at a symposium on Super-stewardship in the Context of Public Health held at the University of Sheffield on 14 November 2009; at the ECPR Regulation and Governance conference ("Regulation in an Age of Crisis"), held 17-19 June 2010, Dublin; and at the conference on Tentative Governance in Emerging Science and Technology, held 28-29 October, 2010, at the University of Twente. I am grateful to all who participated in the symposium and at the two conferences. Needless to say, however, the usual disclaimers apply. In the paper, there are some passing references to issues that might arise from the future operation of UK Biobank. Here, let me emphasise that I am writing purely in my personal capacity and in no sense in my capacity as Chair of the Ethics and Governance Council for UK Biobank.

1 R Brownsword, Rights, Regulation and the Technological Revolution (Oxford: OUP 2008). 
appropriately managed. Stated shortly, the regulatory environment should ensure that the relevant risks are confined to "acceptable" levels. However, a number of more particular questions can be isolated from this general challenge. One such question is that of "prudential pluralism". Where individuals arrive at very different prudential judgments as to the acceptability of particular risks (perhaps because they simply have different thresholds of risk, or because they have different valuations of the off-setting benefits), how are regulators to proceed? Is this where responsible regulators should rely on processes of deliberative democracy? Another question concerns the responsibilities that regulators might have to inform and to guide prudential decision-making. For example, where individuals are invited to participate in screening programmes (for various health conditions), there is no guarantee that they will make the "right" prudential decision (in the sense of the decision that best serves their interests); but, if the risk that they take (whichever way they decide) touches and concerns only them, should regulators try (paternalistically) to steer such decisions one way or the other? A further question arises from the state of uncertainty that often accompanies emerging technologies. Even experts cannot agree on the risk (or benefit) profiles of these technologies. Is this an occasion for responsible regulators to embrace a precautionary approach?

Thirdly, I turn to the role of stewardship. Elsewhere, I have introduced this idea in terms of the regulatory state acting for the collective well-being of the community; ${ }^{2}$ but, this is compatible with many background philosophies. Narrowing things down somewhat, the basic idea is that community life is staged and that the infrastructure that makes up the staging needs special protection - the staging of public health, promoting the conditions for a healthy population, is a fairly straightforward fit with this image. ${ }^{3}$ Following this line of thinking, we can say that, while regulators have ongoing responsibilities in relation to the routine running of community life, they also have stewardship or, let us say, superstewardship responsibilities for the preservation of the staging (the infrastructure) itself.

Developing these ideas, I suggest that there is a "commons" that provides the staging for all communities of (human) agents -a set of conditions that are generic in the sense that they are essential no matter what particular purposes a community and its (human) agent members might choose to pursue. ${ }^{4}$ Communities of (human) agents simply cannot survive without these infrastructural conditions, without the conditions that are conducive to life, well-being, and the opportunity to pursue one's own plans and purposes. Of course, each community will be distinguished by its particular purposes and, relative to those particular purposes, some infrastructural conditions will be essential (in the way, for example, that the infrastructure of financial services is essential to modern market economies). But we need to distinguish between super-stewardship that is generic in relation to communities of (human) agents and simple stewardship that is contingent. To protect the generic commons is to prevent acts that are not simply imprudent but also, unless we are amoralists, immoral (in the sense that they are damaging to the conditions that are essential for others to sustain their legitimate interest in life); to protect contingent infrastructural conditions is to prevent acts that are, relative to at least some agents, imprudent and (again, relative to some lights) immoral.

Arguably, super-stewardship extends beyond the bare conditions of human existence. For, if all agents, simply by virtue of their agency, are rationally committed to a moral way

2 See, R Brownsword, "Rights, responsibility, and stewardship: beyond consent" in H Widdows and C Mullen (eds), The Governance of Genetic Information (Cambridge: CUP 2009), p. 99, at p. 117.

3 Cf. R Brownsword, "Public health, private right: constitution and common law" (2006) 7 Medical Law International 201; and "Public health, private right and the common law" (2006) 120 Public Health 42.

4 For the development of this idea, see R Brownsword, "Friends, Romans, and countrymen: is there a universal right to identity?” (2009) 1 Law, Innovation and Technology 223. 
of life in general (by which, I mean that they are committed to trying to do the right thing), ${ }^{5}$ then regulators need to exercise a super-stewardship responsibility in relation to the essential conditions for moral community. The particular significance of this point is that, insofar as regulators resort to the register of prudence and practicability or possibility, they need to take a hard look at whether this is compatible with maintaining conditions in which regulatees can develop the virtue of doing the right thing for the right reason (as opposed to doing so for reasons relating to prudence, practicability, or possibility). Of course, each moral community will have its own criteria of right action - and, in Rights, Regulation and the Technological Revolution, I argued that we should assume a community of rights as our ideal-typical moral community. In a community of rights, the expectation will be that regulators should strive to ensure that public life and private action is rights compatible; and this might imply a layer of rights-specific stewardship. However, the underlying point is that regulators have a super-stewardship responsibility for those conditions that are presupposed by any kind of moral community (whether a community of rights, a duty-based community, or a community of consequentialist utilitarians).

Finally, how does precaution fit into this web of ideas? Characteristically, the precautionary principle urges regulators to take protective steps (particularly with regard to environmental concerns) even if the evidence of risk is unclear, even if there is scientific uncertainty, even if we cannot specify the probability of the harm eventuating. As many critics have pointed out, such a one-sided plea for precautionary restraint makes little sense in a routine prudential calculation - for, all things considered, the consequences of precaution might be worse than the consequences of continuation. If precautionary reasoning is to make sense, it must be either modified to fit with intelligent prudential calculation or it must be placed in a special context that is distinct from routine prudential calculation. Where super-stewardship is engaged, the thought occurs that we have precisely such a context. Quite what precaution dictates in such a context remains to be discussed but the idea that, where the super-stewardship jurisdiction is triggered, we need no longer worry about the precise degree of probability of harm has some plausibility - responsible regulators simply do not take any kind of risk with the essential infrastructural conditions.

The paper is in six principal parts. In the next two parts (2 and 3), I elaborate respectively the basic idea of a regulatory environment and the challenge of regulatory prudence. In the three middle sections of the paper (4,5 and 6), I introduce the particular issues of prudential pluralism, facilitation of individual prudential judgment, and dealing with uncertainty. This leaves super-stewardship to be discussed in the final part of the paper (7).

\section{The regulatory environment}

In this part of the paper, I offer some remarks that are designed to clarify my idea of the regulatory environment. These remarks relate to:

(i) the basic idea of regulation and the regulatory environment;

(ii) two framing mistakes that we should avoid;

(iii) the key regulatory registers employed by regulators;

(iv) three generations of regulatory environment; and

(v) the way that the intentions of the regulators play in a regulatory environment.

5 Seminally, see A Gewirth, Reason and Morality (Chicago: University of Chicago Press 1978); and see, too, D Beyleveld and R Brownsword, Human Dignity in Bioethics and Biolaw (Oxford: OUP 2001). 


\section{(i) Regulation AND the REgULATORY ENVIRONMENT}

Generally speaking, the idea of regulation is taken to refer to a sustained, focused and organised attempt to steer conduct. As Julia Black puts it, we think of regulation as: the sustained and focused attempt to alter the behaviour of others according to standards or goals with the intention of producing a broadly identified outcome or outcomes, which may involve mechanisms of standard-setting, informationgathering and behaviour-modification. ${ }^{6}$

Regulation is thus operationalised through a combination, or cycle, of direction, detection and correction. It follows that, in a regulatory environment, there will be various signals that are intended to direct the conduct of regulatees; there will be various means of monitoring conduct to see whether the directions are being followed; and, where deviation is detected, there will be measures for correction. In such environments, regulators signal whether particular acts are permitted (even required) or prohibited, whether they will be viewed positively, negatively, or neutrally, whether they are incentivised or disincentivised, whether they are likely to be praised or criticised, even whether they are possible or impossible, and so on. ${ }^{7}$

Whilst some environments are regulated in a top-down law-like fashion (with regulators clearly distinguishable from regulatees), others are more bottom-up, more self-regulatory, and more reliant on "governance" than hard law. Moreover, while some regulatory environments are reasonably stable and well-formed, others are unstable, overlapping, conflictual, and so on.

\section{(ii) TWO FRAMING MISTAKES}

For lawyers, it is natural to centre attempts to understand the social world in distinctively legal types of regulation. For lawyers, it is law that makes the world go round; and it is puzzling that sociologists, whose business it really is to understand the social world, appear to have such little interest in the law. With this focus on law, we need to be careful - and, above all, it is lawyers who need to be careful - to avoid two framing mistakes with regard to the idea of a regulatory environment.

First, there is the mistake of legal exclusivity - which makes the assumption that the only signals in the regulatory environment are formal legal signals. One of the key points about the regulatory environment is that we may find regulators employing a range of mechanisms or modalities that are designed to channel the conduct of their regulatees. Some of these modalities may well be legal. It is not that regulatory environments never feature legal signals; and, in many instances, it will be the legal signals that have the highest profile. Nevertheless, the regulatory repertoire goes well beyond legal signals. Seminally, Lawrence Lessig has identified the following four regulatory modalities: namely, the law, social norms, the market and architecture (or code). ${ }^{8}$ So, for example:

The government may want citizens to wear seatbelts more often. It could pass a law to require the wearing of seatbelts (law regulating behavior directly). Or it could fund public education campaigns to create a stigma against those who do not wear seatbelts (law regulating social norms as a means to regulating

6 J Black, "What is regulatory innovation?" in J Black, M Lodge and M Thatcher (eds), Regulatory Innovation (Cheltenham: Edward Elgar 2005), p. 1, at p. 11.

7 Cf. R Brownsword and H Somsen, "Law, innovation and technology: before we fast forward - a forum for debate" (2009) 1 Law, Innovation and Technology 1.

8 L Lessig, Code and Other Laws of Cyberspace (New York: Basic Books 1999), ch. 7; and L Lessig, "The law of the horse: what cyberlaw might teach" (1999) 113 Harvard Law Review 501, pp. 507-14. 
behavior). Or it could subsidize insurance companies to offer reduced rates to seatbelt wearers (law regulating the market as a way of regulating behavior). Finally, the law could mandate automatic seatbelts, or ignition-locking systems (changing the code of the automobile as a means of regulating belting behavior). Each action might be said to have some effect on seatbelt use; each has some cost. The question for the government is how to get the most seatbelt use for the least cost.?

The significance of these different modalities is not just that there is more than law in the regulatory mix; for, once the modality moves away from law and social norms, to market, architecture and code, the signal to regulatees can change from being normative to non-normative in character.

This takes us to the second framing mistake, the mistake of normative exclusivity - which makes the assumption that the only signals in the regulatory environment are normative (that is, signals that prescribe what ought, or ought not, to be done). Again, laws are normative, as of course are social norms. Market signals might also speak to what ought (or ought not) to be done, not so much as a matter of respect for others but simply what ought (or ought not) to be done in one's own interest. For example, where a "green" tax is added to the price of larger cars or to fuel, we might reason that we ought to drive a smaller car because larger cars are expensive and put a strain on our personal finances. However, if the price of larger cars is increased beyond our means, our reasoning shifts from the normative mode to the non-normative mode of practicability - it is not so much that, as a matter of self-interest, we ought not to buy a large car but that we simply cannot (afford to) do so. When the regulatory modality is that of architecture or code, or the like, we might well find that the signal is one of (non-normative) practicability or possibility. However, as with market signals, there might be elements of both normativity and non-normativity - witness, for example, Mireille Hildebrandt's important distinction between "regulative" (normative) and "constitutive" (non-normative) technological features. ${ }^{10}$ So, for example, if a car is equipped with sensors that can detect alcohol in the driver, it might be designed to respond normatively (by advising that it is not safe for the driver to proceed) or non-normatively (by immobilising the car).

Given that the regulatory environment sets the context for the operation of the law, it is important that we frame our inquiries in the most helpful way. For example, if we are to make informed choices about the right kind of legal intervention, especially about the effectiveness of the intervention, we need to know what other signals are in play in the regulatory environment. Moreover, as the non-normative elements of the regulatory environment gain in importance, we need to address the values of legality (and the rule of law) that we take to be central to civilised social ordering. ${ }^{11}$

\section{(iii) Three Regulatory ReGisters}

We can tighten our grip on the significance of the different regulatory modalities by identifying the key registers that regulators employ to engage the practical reason of regulatees. There are three such registers as follows:

(i) the moral register: here regulators signal that some act, $x$, categorically ought or ought not to be done relative to standards of right action (as in retributive

9 Lessig, Code, n. 8 above, pp. 93-4.

10 M Hildebrandt, "Legal and technological normativity: more (and less) than twin sisters" (2008) 12(3) TECHNE 169.

11 Compare M Hildebrandt and B-J Koops, "The challenges of ambient law and legal protection in the profiling era" (2010) 73 Modern Law Review 428. 
articulations of the criminal law where the emphasis is on the moral nature of the offence); or

(ii) the prudential register: here regulators signal that some act, $\mathrm{x}$, ought or ought not to be done relative to the prudential interests of regulatees (as in deterrence-driven articulations of the criminal law where the emphasis is on the sanction that will be visited on offenders); or

(iii) the register of practicability or possibility: here regulators signal that it is not reasonably practicable to do some act, $\mathrm{x}$, or even that $\mathrm{x}$ simply cannot be done - in which case, regulatees reason, not that $\mathrm{x}$ ought not to be done, but that $\mathrm{x}$ cannot be done (either realistically or literally).

In an exclusively moral environment, the primary normative signal (in the sense of the reason for the norm) is always moral; but the secondary signal, depending upon the nature of the sanction, might be more prudential. In traditional criminal law environments, the signals are more complex. Whilst the primary normative signal to regulatees can be either moral (the particular act should not be done because this would be immoral, or (in Millian liberal orders) the act would be harmful to others) or paternalistically prudential (the act should not be done because it is contrary to the interests of the regulatee), the secondary signal represented by the deterrent threat of punishment is prudential. ${ }^{12}$

Where there is an increasing reliance on regulatory technologies (for example, CCTV, DNA-profiling, radio frequency identification tracking and monitoring devices, and so on $)^{13}$ the strength and significance of the moral signal fades. First, the dominant signal to regulatees tends to be a prudential one, accentuating that the doing of a particular act is contrary to the interests of regulatees (because they will be detected and punished); and, then, in a later drift, the signal becomes that an act is either not practicable (such as trying to board an aircraft for an international flight without going through the security scans) or simply not possible. ${ }^{14}$ Where the signal is that a particular act is no longer a possible option, regulatee compliance is, so to speak, fully determined.

\section{(iv) THREe Generations of REgULATORY ENVIRONMENT}

From time to time, my colleague Karen Yeung helpfully reminds me that (as I had once written $)^{15}$ techno-regulatory strategies might focus on products, places, or persons. Thus, regulators might specify certain safety, or privacy-enhancing, or copyright-protecting features to be designed into products; or they might specify certain architectural features to improve safety (as in the layout of roads), or to facilitate transparency (think about the Bundestag building in Berlin), or adversarial political debate (think about the layout of the House of Commons at Westminster); or, in some future world, they might specify that only those human embryos that have acceptable genetic profiles should be implanted for reproductive purposes.

If we shuffle these ideas, we can imagine three ideal-typical generations of regulatory environment. In a first-generation regulatory environment, regulators would rely exclusively on normative signals. In a second-generation regulatory environment, regulators would rely

12 Compare A Norrie, "Citizenship, authoritarianism and the changing shape of the criminal law" in B McSherry, A Norrie and S Bronitt (eds), Regulating Deviance (Oxford: Hart 2009), p. 13; and L Zedner, "Fixing the future? The pre-emptive turn in criminal justice", ibid. p. 35.

13 Cf. M A Rothstein and M K Talbott, "The expanding use of DNA in law enforcement: what role for privacy?" (2006) 34 Journal of Law, Medicine and Ethics 153, pp. 160-1.

14 Cf. B-J Koops, "Technology and the crime society: rethinking legal protection" (2009) 1 Law, Innovation and Technology 93.

15 See R Brownsword, "Code, control, and choice: why east is east and west is west" (2005) 25 Legal Studies 1, p. 12. 
on both (first generation) normative signals and second-generation design of products and places. Where regulators rely on such a design strategy, the signal might no longer be normative; instead, the design features signal what is practicable or possible (in the way that the smart car is immobilised on sensing drink or drugs in the driver). Finally, in a thirdgeneration regulatory environment, regulators would go beyond traditional normative signals and design of products and places by incorporating the regulatory design within regulatees themselves (for example, by means of pharmacological intervention, or neurosurgery, or by controlling their genetic coding). Where design is embedded in regulatees in such a way that it channels their behaviour, it is likely to be much less apparent to regulatees that they are being regulated - if the design is reliable, regulatees will simply behave (like products or, for that matter, robots) in accordance with their specification.

\section{(v) Design AND INTENTIONALITY}

Finally, there is the matter of regulatory intention and effect. If we are to hold regulators to account, then the paradigm case is one in which they have self-consciously put in place a range of signals that are intended to direct or channel behaviour in a particular way. In such a case, the regulatory environment is purposively produced. However, designs might have regulatory effects even though such effects are not ones that the regulators (designers) intended. So, for example, there has been a long-running debate about whether the design of Robert Moses' bridges on the New York parkways was intended to have the (racially discriminatory) effect of making it more difficult for the poor, mainly black, population to reach the beaches on Long Island. ${ }^{16}$ From the point of view of prospective beach-users, it made little difference whether the bridges had been designed with this intent - in practice, the bridges had the regulative effect of making the beaches more difficult to access. Nevertheless, if we are to hold regulators (designers) to account, is it not the case that their intentions remain important?

The paradigm is one in which regulators have certain channelling purposes, and they put in place a rule framework or a design that is intended to have a particular effect. In such a case, it is perfectly fair to ask regulators to justify both their purposes and the instruments (the rules or the designs) that they have adopted. However, even the best-laid regulatory plans can go awry and, as is all too well known, a common problem with regulatory interventions is that they generate unintended effects. ${ }^{17}$ Clearly, when regulators are held to account, they must answer for both the intended and the unintended effects of the regulatory environments that they have put in place.

Having said this, the case of the New York parkway bridges might seem rather different. In defence of the bridge designers, it might be argued that there was no regulatory plan as such, simply an attempt to strengthen the bridges. To be sure, in practice, the newly constructed bridges might have had a regulative impact, but this was an unintended effect of the design. Once upon a time, such a defence might have been adequate; but, nowadays, regulators will not get off the hook quite so easily. For, as it becomes increasingly clear that design can matter (potentially, having both negative and positive effects), so it is no longer acceptable for regulators to plead a lack of intent, or attention, with regard to such technical details. While inattention may lead to regulatory environments that are detrimental to, say, the health or the privacy of regulatees, smart regulatory action can have the opposite impact (for

16 See N Manders-Huits and J van den Hoven, "The need for a value-sensitive design of communication infrastructures" in P Sollie and M Düwell (eds), Evaluating New Tecbnologies (Dordrecht: Springer 2009), p. 51, at p. 54.

17 For a helpful overview, see S Biegel, Beyond Our Control? (Cambridge MA: MIT Press 2003); and, for some particular cases, see C R Sunstein, "Paradoxes of the regulatory state" (1990) 57 University of Chicago Law Review 407. 
example, by requiring or encouraging architects and technologists to default to healthpromoting or privacy-enhancing designs). ${ }^{18}$ In short, although the paradigmatic regulatory environment is the product of intentional design, regulators need to answer for both the intended and the unintended channelling effects of their actions as well as for their omissions.

\section{(vi) LOOKING AHEAD}

There are a number of ways in which this elaboration of the features of a regulatory environment might assist our understanding of the operation of law. Moreover, there are important pointers to what we should be looking for as regulation becomes less transparent and more reliant on design. However, for present purposes, the particular significance of this discussion will become clear when we turn, later in the paper, to the stewardship responsibilities of regulators.

\section{The challenge of regulatory prudence}

One of the first concerns for any community will be whether a novel technology is safe, whether it presents any risk to human health or safety, or to the environment (the integrity of which is, of course, essential for human health and well-being). There is nothing noble about such concerns; they are entirely self-serving prudential concerns; but, because these are concerns that are common to all humans with the instinct for survival, they are not controversial in themselves. To some extent, individuals can take their own protective measures - for example, an individual who is worried about the safety of mobile phones might decline to use one, or use it only in emergencies, or use it only as a hand-held device operating well away from one's head - but there are limits to how far such protective steps can be taken. Where individuals are employed in workplaces that are equipped with machines, where getting from A to B involves an encounter with road traffic, and so on, it is not reasonably practicable to conduct one's life in a way that maintains a safe distance from industrial and transport technologies. Accordingly, it falls to regulators to protect the public against technologies that give rise to safety concerns; and the challenge of regulatory prudence is essentially one of reducing risk to an acceptable level.

In her excellent account of the way that regulators have responded to emerging technologies, Susan Brenner has suggested that regulators have tended to focus on two forms of harmful use, defective implementation and (intentional) misuse. ${ }^{19}$ In the case of defective implementation, the technology was not being used in a way that was intended to be hazardous; nevertheless, safety issues arose and regulators needed to address them. Regulatory responses can vary, one from the other, and across time. Consider, for example, the case of the bicycle. According to Brenner:

Legislators at first simply banned bicycles from major thoroughfares, including sidewalks. These early enactments were at least ostensibly based on public safety considerations. As the North Carolina Supreme Court explained in 1887, regulations prohibiting the use of bicycles on public roads were a valid exercise of the police power of the state because the evidence before the court showed "that the use of the bicycle on the road materially interfered with the exercise of the rights and safety of others in the lawful use of their carriages and horses in passing over the road." 20

18 See e.g. Manders-Huits and van den Hoven, "The need", n. 16 above; and P-P Verbeek, "The moral relevance of technological artifacts" in Sollie and Düwell, Evaluating New Technologies, n. 16 above, p. 63.

19 S W Brenner, Law in an Era of "Smart" Technology (New York: OUP 2007).

20 Ibid. pp. 36-7. 
Over time, though, the regulatory response to bicycles mellowed so that, by the end of the nineteenth century, bicycle users were being treated on much the same footing as other road users. This meant that there needed to be some rules of the road - for example, in 1897, New York's traffic code "established a speed limit of eight miles per hour and required cyclists to give pedestrians the right of way"; it also "forbade cyclists from coasting on city streets", although at that time opposition from cyclists blocked moves to require the fixing of brakes on bicycles. ${ }^{21}$ With modern technology, brakes are as much a part of the design of the bicycle as are the pedals, and "[m]odern statutes regulate various aspects of cycling, such as limiting how many people can ride a bicycle at one time, specifying how bicycles are to be operated, and requiring helmets for operators and lamps for cycles being operated after dark". 22 Indeed, one might see in modern regulatory measures, a concern not only for the safety of pedestrians and other road users but also a (paternalistic) concern for the safety of the cyclist - such concerns being reflected in an array of measures for safe design and safe implementation.

Moving on from bicycles, what are the prudential concerns that are generated by today's technologies? Some of these technologies, like their predecessors, give rise to straightforward safety concerns but, with others, the concerns relate much more to the health of persons and the protection of the environment. In part, this might be because, in the twenty-first century, following bovine spongiform encephalopathy, thalidomide, contaminated blood products, Chernobyl, and a host of similar causes célèbres, there is a much greater sensitivity to the ways in which our health is affected by the food, drugs and technologies of our time, as well as an awareness of the way in which the cumulative use of technologies can be environmentally damaging. ${ }^{23}$

In one respect, however, we might think that the safety concerns relating to the technologies of the twenty-first century are rather different to earlier regulatory experiences. Today, the following three factors are at work:

(i) for the most part, and in most places, citizens are eager to embrace the benefits of new technologies (they are largely technophiles);

(ii) at the same time, however, citizens are highly risk-averse; and,

(iii) there is a great deal of uncertainty surrounding both the benefits and, particularly, the risks of new technologies - for example, there is uncertainty about the impact of genetically modified organisms on the environment; there is uncertainty about whether unfixed nanoparticles might be the new asbestos; there is uncertainty about both the benefits and the risks associated with synthetic biology, and so on.

The interaction between these factors sets up a number of tensions and regulatory dilemmas. For example, how are the risks to be balanced against the benefits? And, when scientists are unable to assure citizens as to the safety of particular technologies, how should regulators proceed? If zero risk is not an option, then the challenge of prudence is one of finding the level at which risk is judged to be acceptable. But how is acceptability to be judged when both risks and benefits are viewed differently from one person to another, as well as being assessed quite differently by experts?

In such a contested context - and, moreover, in a context of rapid social and technological change - what are the requirements of responsible regulation? I suggest that regulatory prudence presents three major challenges: first, to find an acceptable way of

21 Brenner, Law in an Era, n. 19 above, p. 39.

22 Ibid.

23 See e.g. G Little, "BSE and the regulation of risk" (2001) 64 Modern Law Review 730. 
dealing with prudential pluralism; secondly, to decide how far there is a responsibility to facilitate informed prudential decision-making by individuals (or even to steer decisions more directly); and, thirdly, to find an adequate way of handling scientific uncertainty. In the next three parts of the paper, we can begin to think through these particular challenges.

\section{Responsible regulation I: dealing with prudential pluralism}

Pluralism signifies that that there are a number of different views about a particular matter. However, there are many reasons why people can have different views and some reasons are far more fundamental than others. Sometimes, nothing of any moment rides on our differences - for example, it is easy for me to live with your preference for Thai curries and, conversely, for you to live with my preference for Indian curries. In some cases, our differences might even be complementary but, on occasion, they can be conflictual. Suppose, for example, that you are a vegetarian and I am not, but that we both believe that it is important to respect the welfare of animals; here, we agree on a matter of first principle (concerning respect for animals) but we disagree about the application of the principle. Faced with such a difference, we might reasonably agree to disagree. However, if we also dispute the first principle - suppose that I deny that we have any responsibility for animal welfare - then our differences go much deeper and it is more difficult for us to let the matter rest. And, in the same way, where differences do matter and where they go deep, it is more difficult for regulators to shrug off their responsibilities.

To see what precisely the issue is in relation to prudential pluralism, our first step is to clarify the nature of a prudential judgment (as against an ethical judgment); then, we can assess the appropriateness of deliberative democracy, both in principle and in practice, as a responsible regulatory response to prudential pluralism.

\section{(i) Prudential pluralism}

Paradigmatically, a "prudential" judgment is one that is directed at identifying what is in one's own interest; such a judgment is intended to be entirely self-serving. Thus, for example, agent A might prudentially judge that it is, or is not, in his or her self-interest to undergo surgery or to be tested or screened for some condition. It is a matter of weighing the costs and the benefits and judging where the balance of self-interest lies. In making such a judgment, $\mathrm{A}$ takes no account whatsoever of the interest of others.

As against a prudential judgment (where A judges only what is in A's own interest), an "ethical" judgment involves judging what is in the legitimate interests of all affected "parties", both oneself and others. To act ethically is to try to do the right thing, not just relative to one's own interests but relative to the legitimate interests of both oneself and others. In practice, there will often be a convergence between a prudential judgment that takes into account the judging party's longer-term self-interest and an ethical judgment - as a result of which it might be difficult, at times, to detect whether an act that gives weight to the interests of others is motivated by prudential or ethical reasons. In principle, however, the difference between a prudential and an ethical judgment - and, concomitantly, the difference between a prudential and an ethical plurality - is clear.

As we have said, where agents are each invited to make their own prudential judgment about a matter, there are likely to be a number of different judgments made. For example, whereas agent $\mathrm{A}$ might be persuaded that it is in his interest to drink a glass of claret each day, judging that the anticipated benefits outweigh the costs, agent $\mathrm{B}$ might value the benefits and calculate the costs differently, leading to the judgment that prudence does not dictate such consumption. Of course, the way in which these prudential judgments come out might have a practical impact on those who are involved in the wine industry but the 
prudential pluralism that exists between A and B does not, as yet, invite regulatory attention. However, once the prudential preferences of $\mathrm{A}$ and $\mathrm{B}$ in relation to some particular matter $\mathrm{x}$ are no longer compatible, then regulators have to lay out the ground rules - regulators have to decide whether to prohibit or permit $\mathrm{x}$; and, where they decide to permit $\mathrm{x}$, they have to decide on what terms $\mathrm{x}$ is to be permitted.

Suppose, for example, that regulators are pressed to set a framework for the safe research and development of synthetic biology or the safe application of nanomedicine. This is not usually understood as a demand for zero risk but that regulators should set standards that manage the risk at an acceptable level. ${ }^{24}$ However, what constitutes an acceptable risk will depend upon how the costs and benefits are calculated. While agent A, who is highly risk averse, may judge, prudentially, that synthetic biology should be prohibited or, at least, subjected to a moratorium, agent B, who is a biotechnological entrepreneur, might take a radically different view. The views of $A$ and $B$, it must be emphasised, are not the least bit noble; it is purely and simply a matter of A and B making judgments that each calculates to be self-serving; A, in making his prudential judgment, takes no account of B's preferences or interests; and B, in making her prudential judgment, takes no account of A's preferences or interests.

\section{(ii) Deliberative Democracy IN PRINCIPLE}

Where a regulatory position needs to be taken, how should regulators respond to a prudential plurality? In a democracy, there is a reasonable expectation that there will be a process of public engagement before a position is taken. Before settling upon a legal framework, there needs to be a process that ascertains public opinion, that seeks out a reasonable position, and then that adopts a regulatory position that reflects a reasonable view about an acceptable level of risk.

When Professor Amy Gutmann was appointed to chair the (US) Presidential Commission for the Study of Bioethical Issues (and first tasked to report on the implications of synthetic biology), she declared that it was her intention to champion informed debate in the spirit of deliberative democracy. ${ }^{25}$ According to Professor Gutmann, deliberative democracy, in contrast to "sound-bite democracy", is about engaging the public:

Deliberative democracy is about . . . listening to competing points of view, considering opposing arguments and coming to a decision that ideally finds common ground - or at least respects competing points of view. ${ }^{26}$

On the face of it, this is a promising strategy, not only for handling ethical pluralism but also for dealing with prudential pluralism. For deliberative democracy, as elaborated by Professor Gutmann, ${ }^{27}$ decrees that all freely expressed views are to be heard and that, so long as they are not wholly unreasonable, they are to be accorded equal consideration. At the end of the process, differences should have been minimised and regulators should be in a position to act on reasons that are at least acceptable to all persons who are committed to fair terms for political and social cooperation. To be sure, this does not quite guarantee

24 Cf. e.g. the European Group on Ethics in Science and New Technologies to the European Commission, Opinion on the Ethical Aspects of Nanomedicine (Opinion No 21, 2007), para. 4.2.3: "risk management actions should be aimed at identifying the 'acceptable risk' threshold with regard to the values at stake - and respect for the human body is undoubtedly one of the values deserving the highest legal protection".

25 See, M Wadman, "Bioethics gets an airing", Nature, 7 July 2010, available at www.nature.com/news /2010/070710/full/news.2010.340.html.

26 Ibid.

27 See A Gutmann and D Thompson, Why Deliberative Democracy? (Princeton: Princeton UP 2004). 
that the eventual outcome will attract everyone's vote; but, because the decision in question will be supported by acceptable reasons, reasonable people should respect it. Moreover, it is characteristic of Professor Gutmann's version of deliberative democracy that debates can be re-opened; decisions are, thus, reviewable, which means that the time might still come for today's dissenting views. In this way, scientific research and the development of associated technologies can proceed leaving pluralistic societies to settle their differences in a civilised way. ${ }^{28}$

\section{(iii) Deliberative democracy IN ACtion}

Even if deliberative democracy seems like an appropriate regulatory response to prudential pluralism, and even if we can assume that the purposes that underlie the engagement of the public are in the best sense democratic (and not merely an attempt to "educate" the public in a way that "legitimates" emerging technologies), ${ }^{29}$ this is far from being a straightforward exercise in public consultation and debate. ${ }^{30}$ For example, how are researchers to cope with what can be extremely variable levels of public understanding of the technology; 31 how are they to distil attitudes towards a particular technology from a medley of predispositions (to science, technology, commerce, and so on); and how are they to overcome the public's suspicion of stakeholders in the technology? ${ }^{32}$

How might these obstacles be overcome? In the influential report by the Royal Society and the Royal Academy of Engineering, Nanoscience and Nanotechnologies: Opportunities and uncertainties, 33 it is recommended that: dialogue and engagement should occur early, and before critical decisions about the technology become irreversible or "locked in"; dialogue should be designed around clear and specific objectives; the sponsors should publicly commit to taking account of the outcome of the engagement process; dialogue should be properly integrated with other related processes of technology assessment; and resourcing for the dialogue should be adequate. ${ }^{34}$ Even with attention to these matters, however, there

28 In its ensuing report (see the Presidential Commission for the Study of Bioethical Issues, New Directions: The ethics of synthetic biology and emerging technologies (Washington, December 2010)), the commission identifies five key principles (namely, public beneficence, responsible stewardship, intellectual freedom and responsibility, democratic deliberation, and justice and fairness). The "principle of responsible stewardship rejects two extreme approaches: an extreme action-oriented [proactionary] approach that pursues technological progress without limits or due regard for public or environmental safety, and an extreme precautionary approach that blocks technological progress until all possible risks are known and neutralized" (p. 26). Instead, as a middle way between proaction and precaution, the commission advocates "the development of agile, measured oversight mechanisms" (ibid.). In other words, "[r]esponsible stewardship calls for prudent vigilance, establishing processes for assessing likely benefits along with safety and security risks both before and after projects are undertaken" (p. 27) (original emphasis). For further elaboration of prudent vigilance as an articulation of responsible stewardship, eschewing both extreme proaction and precaution, see ibid. pp. 123-4.

29 For a critical commentary on EU governance in this regard, see M L Flear and A Vakulenko, "A human rights perspective on citizen participation in the EU's governance of new technologies" (2010) 10 Human Rights Law Review 661.

30 Cf. e.g. International Risk Governance Council (IRGC), Risk Governance of Synthetic Biology (Geneva: IRGC 2009); and S Davies, P Macnaghten and M Kearnes (eds), Reconfiguring Responsibility: Lessons for public policy (Part 1 of the report on Deepening Debate on Nanotechnology) (Durham: Durham University 2009).

31 Synthetic biology is just such a case in point: see the findings in Royal Academy of Engineering, Synthetic Biology: Public dialogue on synthetic biology (London: Royal Academy of Engineering, June 2009).

32 See R Sheldon, N Cleghorn, C Penfold, A Brown and T Newmark, Exploring Attitudes to GM Food (London: Social Science Research Unit, Food Standards Agency, 24 November 2009); and, S Jasanoff, Designs on Nature (Princeton: Princeton UP 2005), p. 129 (for a somewhat negative assessment of the public debate on genetically modified foods in the UK).

33 Royal Society Policy document 19/04 (London: July 2004).

34 Ibid. para. 38. 
might be doubts about how fully the public is engaged; and, of course, it is difficult to immunise a citizens' jury against the influence of the media.

Assuming, though, that the public can be adequately engaged, their prudential calculations are likely to be varied and, concomitantly, their preferred regulatory responses will be at different points of the spectrum from outright prohibition to simple permission or even promotion. Still, in a democracy, this is the stuff of preferences and politics; decisions that are made today can be revised tomorrow; and, while this might not be the ideal way of accommodating the variety of self-interested views, it is a civilised way of living with pluralism. Accordingly, even if the realisation of deliberative democracy is challenging, it appeals as the right way to deal with prudential pluralism. ${ }^{35}$

\section{Responsible regulation II: facilitating (and steering) individual prudential calculation}

In the easy case, where agents can make their personal prudential calculations without this raising any problems of incompatibility, is there any reason for responsible regulators to act? Should they simply leave agents to their own prudential devices; or, where there is a risk that ill-informed decisions might be made, should regulators take steps to educate and inform the parties; and, where the decisions concern, for example, the longer-term wellbeing of agents, should regulators tilt the decision-making context in a way that they (the regulators) think will serve such longer-term interests?

We can speak briefly to the responsibility to educate and inform; and then we can turn to the setting of defaults that "nudge" agents towards particular decisions (or actions). ${ }^{36}$

\section{(i) INFORMING}

If the question concerns a matter about which there is little reliable information, then we might expect regulators to take steps to ensure that the public is properly informed. In other words, regulators should take reasonable steps to ensure that, if there is to be a plurality, it is at least based on a correct understanding of the respective risks and benefits. However, this runs into at least two complications.

First, the reason why the information lacks clarity might be because the experts themselves broadcast mixed messages. Provided that regulators summarise the differences in an intelligible way, this is as much as can be done to facilitate informed prudential decisionmaking. Beyond this, however, we might want regulators to turn their attention to the environment in which research is conducted. If the reason that the expert community is divided is that there is a lack of integrity, then responsible regulators have more work to do. ${ }^{37}$

Secondly, in some cases - for example, where healthcare professionals want to steer agents towards a particular test, screen or procedure - there might be a tension between the professional paternalistic judgment as to what is in an agent's best interest and the agent's

35 See R Brownsword, "Regulating the life sciences, pluralism, and the limits of deliberative democracy" (2010) 22 SACLJ 801.

36 See, R H Thaler and C R Sunstein, Nudge: Improving decisions about health, wealth, and happiness (New Haven: Yale UP 2008).

37 Cf. e.g. O O’Neill, Autonomy and Trust in Bioethics (Cambridge: CUP 2002), p. 120: “There are cases of outright fraud that go beyond disingenuous communication and evasion: scientists, biotech companies and journalists all sometimes misreport and exaggerate the significance of new discoveries; scientific misconduct and fraud sometimes arise from competition for grants, results and glory; peddlers of untried and untested remedies sometimes prey on desperate people. Sporadic deception can be found almost anywhere: among scientists tempted to falsify experimental data; among government agencies tempted to keep worrying medical or scientific facts confidential; among journalists tempted to exaggerate and sensationalise biomedical 'stories'; among campaigning groups eager to persuade the public of their views." 
own prudential judgment. Unless we think that regulators should be aiding and abetting professional paternalism, there is a responsibility to ensure that the information is framed and presented in the way that facilitates autonomous prudential decision-making. ${ }^{38}$

However, no one should be under any illusions about how tricky this is. Those who are providing the information have to decide what to include and what to omit, what to highlight in the foreground and what to relegate to the background as well as judging what is common ground, what is controversial, and what is plain crazy. ${ }^{39}$ This is not to say that informers should abandon their attempts to put prudential decision-makers in the picture as impartially as they can; but, where the picture is contested, there is no neutral presentation.

\section{(ii) NudGING}

Suppose that a screening programme for a particular condition, for example, for prostate cancer, is adopted. We assume that the target male population will be invited to take the appropriate test - that is, we assume this because this is the way that screening programmes are usually rolled out. However, this is just one of a number of possible default positions for a screening programme. For example, the default might be:

D1 general notice of the screening programme is given; but no one is specifically invited to participate; the onus is on men to request the test (general notice opt-in); or,

D2 target males are personally notified about the screening programme but it is left to individuals to request the test (personal notice opt-in); or

D3 target males are personally notified about the screening programme, they are given an appointment for the test and they are expected to take the test unless they expressly indicate otherwise (personal notice opt-out).

No doubt these defaults can be finessed in various ways. However, the point is that, although target males have the option in all cases of taking or not taking the test, D3 steers much more strongly towards the test than D1; and, human nature being what it is, it is likely that the take-up rate under D1 will be low in contrast with a high take-up rate under D3.

Where it is simply not possible to operate without a default position, the question arises whether regulators should self-consciously endeavour to "nudge" regulatees towards acts or lifestyles that regulators judge to be in the longer-term interest of regulatees. This was a strategy, a simple kind of stewardship, that appealed to the Nuffield Council on Bioethics (the Council) in its report on the ethics of public health. ${ }^{40}$

In this report, the Council takes as its guiding standard Millian liberal principles modified by a principle of state stewardship. ${ }^{41}$ While the liberal principles resist the idea that coercion may be legitimately applied against an agent unless their conduct creates a clear and present threat of harm to others, stewardship extends the range of legitimate state intervention (although, according to the Council, coercive measures should be treated as a last resort). The resulting stewardship model holds that legitimate public health interventions should:

38 See, for discussion, R Brownsword and J Earnshaw, "Controversy: The ethics of screening for abdominal aortic aneurysm” (2010) Journal of Medical Ethics 827.

39 Cf. e.g. A Stirling, “'Opening up' and 'closing down': power, participation, and pluralism in the social appraisal of technology” (2008) 33 Science, Technology, and Human Values 262.

40 Nuffield Council on Bioethics, Public Health: Ethical issues (London: Nuffield Council on Bioethics, November 2007).

41 Ibid. ch. 2. 
- aim to reduce the risks of ill health that people might impose on each other;

- aim to reduce causes of ill health by regulations that ensure environmental conditions that sustain good health, such as the provision of clean air and water, safe food and decent housing;

- pay special attention to the health of children and other vulnerable people;

- promote health not only by providing information and advice, but also with programmes to help people to overcome addictions and other unhealthy behaviours;

- aim to ensure that it is easy for people to lead a healthy life, for example, by providing convenient and safe opportunities for exercise;

- ensure that people have appropriate access to medical services; and

- $\quad$ aim to reduce unfair health inequalities. ${ }^{42}$

Although the legitimacy of these interventions is not predicated on obtaining each individual's informed consent, the Council recognises that, wherever possible, it is better to respect personal choice and individual consent, as well as avoid coercive measures. Accordingly, the stewardship version of liberalism specifies that public health programmes should:

- not attempt to coerce adults to lead healthy lives;

- minimise interventions that are introduced without the individual consent of those affected, or without procedural justice arrangements (such as democratic decision-making procedures) which provide adequate mandate; and

- seek to minimise interventions that are perceived as unduly intrusive and in conflict with important personal values. ${ }^{43}$

Some of these extensions of Mill are relatively easy cases for stewardship - for example, interventions that address the care of children, that provide information about the risks to health associated with certain foods, drinks, or lifestyles, that offer facilities that are designed to help to overcome addiction, and the like. ${ }^{44}$ Few, too, would question the state's responsibility for securing the basic environmental conditions that are essential for public health. However, this aspect of the state's responsibility is given a subtle twist once we extend it to a self-conscious staging of everyday circumstances so that they are defaulted in a way that is conducive to public health. Nevertheless, provided that the default setting (say, for walking or using stairs) co-exists with alternatives (say, for riding or using lifts or escalators), this seems to keep faith with Millian liberal principles while exercising stewardship in a way that tilts conditions towards public health. ${ }^{45}$

42 Nuffield Council on Bioethics, Public Health, n. 40 above, para. 2.44.

43 Ibid. These constraints are open to a number of interpretations. In a community of rights, they would be expressed in a more focused, rights-respecting way.

44 See, further, T Baldwin, R Brownsword and H Schmidt, "Stewardship, paternalism and public health: further thoughts" (2009) Public Health Ethics 1.

45 More controversially, the Council also relies on stewardship to reduce unfair health inequalities. Clearly, any manifesto that aspires to equalise the conditions of public health or to eliminate unfairness in access to health resources is open to interpretation. However, insofar as these extensions relate closely to the conditions that are judged to be essential for any prospect of agency, this seems to me to be entirely defensible relative to the broad commitments of a community of rights. 
While it is arguable that setting the defaults in a way that is paternalistic, but that still gives agents an opt-out possibility, is compatible with respect for individual autonomy, ${ }^{46}$ is this an appropriate exercise of prudential regulatory responsibility? What if regulatees prefer different defaults? I have already said that regulators need to be sensitive to the effects of their designs (in this case defaults) and these paternalistic defaults might well display a wellintended public health sensitivity. However, sensitivity is not enough; regulators need to be aware of their regulatees' preferences as well as rendering the defaults transparent. In other words, autonomy with a tilt or a nudge is all very well, but responsible prudential regulation needs to display the standard public law virtues of due process and transparency before it prioritises paternalism over general preferences. ${ }^{47}$

\section{Responsible regulation III: dealing with uncertainty}

With emerging technologies, there are many matters about which there can be uncertainty. So far as prudential risk/benefit calculations are concerned, the four key points of potential uncertainty relate to: (i) the nature of the possible harms; (ii) the likelihood of the harms eventuating; (iii) the nature of the possible benefits; and (iv) the likelihood of the benefits eventuating. Where the uncertainty relates to the type or likelihood of harm, one view is that responsible regulation implies a precautionary approach. Of course, much has been written about the precautionary principle, much of it critical and dismissive, and some might share Gary Marchant and Douglas Sylvester's judgment that the principle is "an overly-simplistic and under-defined concept that seeks to circumvent the hard choices that must be faced in making any risk management decision". 48

Despite this kind of criticism, the view persists that responsible regulation displays both prudence and, in some cases, precaution. As the Appellate Body at the World Trade Organisation remarked in the Hormones dispute, "responsible, representative governments commonly act from perspectives of prudence and precaution where risks of irreversible, e.g., life-terminating, damage to human health are concerned." 49 Moreover, the principle has a foothold in many regulatory regimes, as highlighted by Annex II of the European Commission's communication on the precautionary principle, ${ }^{50}$ in which the leading occurrences of the principle in international law are listed. What, then should we make of this?

First, although Principle 15 of the Rio Declaration in 1992, enjoining states to take measures to prevent serious and irreversible damage to the environment even if there is a "lack of full scientific certainty", is the most commonly cited expression of the principle, it has no authoritative formulation as such. If, as Neil Manson has suggested, all versions of the principle specify a particular "damage" condition, a particular "knowledge" condition, and a particular "remedial" condition, ${ }^{51}$ each of which can be specified in many different ways, then there are (at least) dozens of possible formulations of the principle. It is essential, therefore, to try to put the principle in its most defensible form.

46 Cf. the idea of "libertarian paternalism" elaborated by C Sunstein (with R Thaler) in Laws of Fear (Cambridge: CUP 2005), ch. 8.

47 Regulators also need to take care that a nudge does not become so strong that opt-out is no longer a realistic option. When nudges shade into something stronger, the regulatory register changes from normative to nonnormative, from ought to can (or cannot).

48 G E Marchant and D J Sylvester, "Transnational models for regulation of nanotechnology" (2006) 34 Journal of Law, Medicine and Ethics 714, p. 722.

49 EC Measures Concerning Meat and Meat Products (Hormones), Report of the Appellate Body W'T/DS26/AB/R, WT/DS48/AB/R, 16 January 1998, para. 124.

$50 \operatorname{COM}(2000) 1$, Brussels, 2 February 2000.

51 N Manson, "Formulating the precautionary principle" (2002) 24 Environmental Ethics 263. 
Secondly, it is important to clarify whether the principle is intended to knock out a poor excuse for inaction (namely a lack of scientific certainty) or to insist upon precautionary action (scientific uncertainty notwithstanding). Whereas the Rio Declaration reads as though it is pushing for action, some articulations - particularly those that focus on specifying the threshold conditions for intervention - imply some resistance to action; 52 and yet others present the principle as being broadly enabling but without disclosing any obvious bias either towards or against intervention. 53 If, as René von Schomberg argues, the modest (but radical) function of the principle is to resist political actors using or abusing "a persistent dissent among scientists as a reason (or excuse) for not taking action at all",54 precaution is clearly in line with regulatory responsibility; for it surely would be irresponsible if regulators routinely refused to interfere until the expert community achieved consensus (for example, until there was full scientific agreement that smoking tobacco causes lung cancer and heart disease).

Thirdly, it follows that the more controversial versions of the principle will be those that advocate regulatory action, scientific uncertainty notwithstanding. To simplify, let us suppose that the nature of the uncertainty concerns the likelihood of activity x causing harm y. Some experts put the likelihood higher than others; but, of course, the range of difference and where it lies on the scale of probability could be almost infinitely variable. For example,

(i) everyone puts the likelihood as higher than $50 / 50$, but the difference ranges from $60 / 40$ to $90 / 10$; or

(ii) everyone agrees that the likelihood is lower than $50 / 50$, but the difference ranges from $40 / 60$ to $10 / 90$; or

(iii) while some put the likelihood as higher than $50 / 50$, others put it as lower than $50 / 50$, with the difference ranging from $90 / 10$ to $10 / 90$.

Other things being equal, it would be irresponsible not to take precautionary action in the first of these scenarios (because, although there is some uncertainty, the experts agree that it is more likely than not that $\mathrm{x}$ causes $\mathrm{y}$ ); but, the case for precautionary action is much less clear in the other cases unless x can be given up with no loss of benefit (or unless the culture in the community is particularly risk-averse).

Fourthly, this last point cues in the objection that it cannot be responsible or rational to introduce a regulatory prohibition on $\mathrm{x}$ (which might or might not be causing $\mathrm{y}$ ) without taking into account the cost of giving up $\mathrm{x}$ (or, the loss of benefit associated with $\mathrm{x}$ ). ${ }^{55}$ Without doubt, in a prudential calculation (which is what we are taking this to be), the loss of benefit must be weighed. Accordingly, even in the scenario where the experts agree that it is more likely than not that $\mathrm{x}$ causes $\mathrm{y}$, it would not be prudent to sacrifice $\mathrm{x}$ without weighing the costs of doing so. This means that the prudential calculation is complex (the

52 See e.g. Pfizer [2002] ECR II-3305, para. 143: “a preventive measure cannot properly be based on a purely hypothetical approach to risk, founded on mere conjecture which has not been scientifically verified". So, mere conjecture and hypothesis will not suffice. Moreover, the underlying science must be consistent with principles of "excellence, transparency and independence" (para. 172).

53 Cf. e.g. the Nuffield Council on Bioethics, Genetically Modified Crops: The etbical and social issues (London: Nuffield Council on Bioethics 1999), p. 162, where the principle is expressed as permitting the imposition of restrictions "on otherwise legitimate commercial activities, if there is a risk, even if not yet a scientifically demonstrated risk, of environmental damage".

$54 \mathrm{R}$ von Schomberg, "The precautionary principle and its normative challenges" in E Fisher, J Jones and $\mathrm{R}$ von Schomberg (eds), Implementing the Precautionary Principle: Perspectives and prospects (Cheltenham: Edward Elgar 2006), p. 19, at p. 23.

55 See Sunstein, Laws of Fear, n. 46 above. 
certain loss of $\mathrm{x}$ against the likely prevention of $\mathrm{y}$; but the critics are surely correct in holding that it is not responsible to try to avoid this complexity by simply taking the precautionary option.

Fifthly, can we imagine a scenario in which precaution is automatically privileged despite (i) there being uncertainty about the likelihood of $x$ causing $y$ and (ii) the loss of benefit if $\mathrm{x}$ is given up? In other words, is there any room in a world of prudent and responsible regulation for a pure precautionary intervention? Cass Sunstein, having been perhaps the sternest critics of a one-eyed precautionary principle, ${ }^{56}$ has sought a more plausible version of the principle by putting it in the context of possible catastrophic harm (in other words, where y represents a catastrophic loss). ${ }^{57}$ Some of the worst-case (or catastrophic) scenarios that Sunstein hypothesises are ones in which the likelihood of $\mathrm{x}$ causing $\mathrm{y}$ is known. However, he also discusses some scenarios in which the likelihood of $\mathrm{x}$ causing $\mathrm{y}$ is not known, in which there is uncertainty. It is in this latter kind of scenario that regulators might appeal to a special form of precautionary principle. For Sunstein, the best formulation is on the following lines:

In deciding whether to eliminate the worst-case scenario under circumstances of uncertainty, regulators should consider the losses imposed by eliminating that scenario, and the size of the difference between the worst-case scenario under one course of action and the worst-case scenario under alternative courses of action. If the worst-case scenario under one course of action is much worse than the worst-case scenario under another course of action, and if it is not extraordinarily burdensome to take the course of action that eliminates the worst-case scenario, regulators should take that course of action. But if the worst-case scenario under one course of action is not much worse than the worst-case scenario under another course of action, and if it is extraordinarily burdensome to take the course of action that eliminates the worst-case scenario, regulators should not take that course of action. ${ }^{58}$

Rightly, Sunstein concedes, that this is "too vague" to operate as a decision rule. ${ }^{59}$ For instance, what would make one worst-case scenario so much worse than another? Would the difference be self-evident? What would make a cost "extraordinarily burdensome"? Still, it puts down a marker for precaution under conditions of uncertainty: if regulators cannot rule out the possibility of catastrophe, they should consider taking steps (that are not disproportionate) to avert that possibility.

This seems to me to be on the right track. However, rather than putting this generally in terms of catastrophic harm, I suggest that the relevant harm is to the generic infrastructure for human existence (the agency commons). Faced with the possibility of such catastrophic harm (for example, if there is reason to fear that particle accelerators might provoke a "strangelet" disaster that reduces the planet to a tiny inert hyperdense sphere), regulators surely have a prudential responsibility to act - if only by temporarily suspending the suspect activity $\mathrm{x}$. Yet, some question the rationality of such a precautionary intervention. For example, Fritz Allhoff, Patrick Lin, and Daniel Moore argue: 60

First, it allows extremely low probabilities to derail entire activities ... Second, these low probabilities - which nevertheless establish possibility - could be

56 Sunstein, Laws of Fear, n. 46 above.

57 Cf. C R Sunstein, Worst-Case Scenarios (Cambridge MA: Harvard UP 2007), esp. ch. 3.

58 Ibid. pp. 167-8.

59 Ibid. p. 168.

60 F Allhoff, P Lin and D Moore, What is Nanotechnology and Why Does It Matter? (Chichester: Wiley-Blackwell 2010), p. 91. 
effectively impossible to reduce to zero ... the precautionary approach . . . becomes paralysing. Third, this is simply irrational ... it is completely irrational to allow remote risks to entirely preclude our consideration of the associative benefits for some course of action.

But this stretches the context (of possible, yet uncertain, harm to the infrastructure) in which the proposed precautionary principle is to be applied, that is, a context in which the point is that we cannot say that the probability of catastrophe is "extremely low"; and nor can we assume that the risk is "remote". Even with this correction, however, is it a fair objection that precautionary super-stewardship is productive of paralysis as well as irrational in foregoing the associative benefits?

I suggest that this objection is misconceived. If regulators know that an activity is harmful to the infrastructure, it would be the height of irresponsibility not to intervene. Quite simply, if the infrastructure is harmed, there will be no beneficial (superstructural) activities to paralyse or derail. If, however, regulators are not certain that an activity is harmful to the infrastructure, but they cannot rule out such a possibility, then the question is whether they should be granted a jurisdiction to intervene. This might be an exceptional scenario but this is precisely what pure precautionary reasoning involves. In other words, in its purest form, quite different to simple or complex prudential reasoning that involves balancing likely harms and benefits, there is a special (and probably very limited) version of the precautionary principle holding that the protection of the infrastructural conditions is so important that, where the possibility of activity $\mathrm{x}$ causing harm to infrastructural condition y cannot be ruled out, $\mathrm{x}$ should be restrained even though this involves a loss of benefit - at any rate, this special principle holds unless the benefit that is lost also relates to the maintenance of the infrastructure. In this scenario, prior to taking such restraining action (rather like a court issuing an interlocutory injunction), regulators need not attempt to estimate more precisely the likelihood of $\mathrm{x}$ causing harm to $\mathrm{y}$, and nor need they attempt to weigh the loss of a beneficial activity (x) against the possible protection of the infrastructure.

It is with this idea of regulators acting to protect the generic infrastructural conditions that we get to the notion of super-stewardship.

\section{Super-stewardship}

For any human community, it is imperative that the generic infrastructural conditions are properly protected. This is the first responsibility of regulators. There is a sense in which the tragedy of the commons is far more serious than a tragedy of the anti-commons. But, of course, a tragedy of the anti-commons is extremely serious; and regulators need to be thinking not only about protecting the essential infrastructure but also setting an environment that enables humans to flourish in their transactions and interactions. For a community with moral aspirations, what this particularly means is that the regulatory environment must leave space for moral development; and, to recall our earlier discussion, this means that reliance on prudential signals and design fixes should not leave regulatees unable to do the right thing for the right reason. Accordingly, in an aspirant moral community, we can think of regulators having a super-stewardship responsibility for the protection and preservation of the essential infrastructural conditions as well as for the generic conditions that are conducive to any kind of moral life.

Let me conclude, then, with some short remarks about regulatory super-stewardship, the agency commons and the conditions for moral community. 


\section{(i) REGULATORY SUPER-STEWARDSHIP AND THE AGENCY COMMONS}

The regulatory environment comprises signals and steering mechanisms that are intended to direct the actions, transactions and interactions of regulatees. However, this already presupposes a stage on which such activities are viable; it presupposes an infrastructure. The general idea of an infrastructure as the underlying foundation for a system is reasonably settled; and the conventional wisdom is that infrastructures in this sense are found in transportation and communication systems, as well as being constituted by basic public services such as sewers, water and energy. ${ }^{61}$ By way of illustration, consider the regulatory environment for a railway system. That environment regulates the movement of rolling stock on the tracks and the conduct of passengers who are carried on the trains. It is an environment that is, literally, thick with regulatory signals. It is also an environment where we find non-normative design replacing (largely for reasons of safety ${ }^{62}$ but also to inhibit free-riding) traditional normative signals. None of this is viable, however, without a supportive infrastructure, without a track.

Now, we can draw a distinction between those infrastructural features that are generic and, thus, essential for any human activity and those that are specific to particular activities. While the railway infrastructure is necessary for a railway transport system, it is not generic. It is not even generic in the context of transport systems because waterways and road traffic, for example, can function perfectly well in the absence of a railway infrastructure; and it is certainly not generic in the broader sense of being essential for any kind of activity to be viable. What, then, might be candidates for the generic infrastructure in this broader and most fundamental sense?

One thing that humans must have before they are capable of acting, transacting or interacting in the purposive (goal-directed) way that we associate with agency is a minimal level of health and well-being. For humans whose basic health and well-being is under threat, there is little prospect of actualising their agency - it is akin to the train system being paralysed by damage to the tracks. Immediately, this gives rise to two difficult questions. First, what are the elements that are relevant to an agent's basic health and well-being? And, secondly, where do we draw the line between the generic infrastructure, specific infrastructures and activities on these infrastructures?

Turning to the first of these questions, let us suppose that we have a rough sense of what it means to say that a human enjoys basic health and well-being. Rather than asking what factors are conducive to such a condition, we can readily identify the kind of factors that are antithetical to such a condition. For example, we can point to problems with food security and clean water, to environmental pollution, and to the prevalence of disease. Sadly, chronic conditions of this kind can be found in many parts of the world and, following a natural disaster, we will often see some of these conditions in an acute form. In these cases, we can say that the infrastructure is deficient or, in the case of an emergency, that it has collapsed.

This leads to the second question. How do we draw the line between the generic infrastructure, specific infrastructures and activities on these infrastructures? In the light of what we have already said, I suggest that it is not too difficult to distinguish between generic and specific infrastructures. To return to railway systems, their specific infrastructures are important and valued; they enhance agency but they are not essential to it. Human agency does not presuppose railway tracks, roads, or any other kind of transport

61 Cf. B M Frischmann, "An economic theory of infrastructure and commons management" (2005) 89 Minnesota Law Review 917, pp. 923ff.

62 Cf. J Wolff, "Five types of risky situation” (2010) 2 Law Innovation and Technology 150. 
infrastructure. These are not part of the generic infrastructure. We might say much the same about the infrastructural elements of a modern information technology system. Cybercrime is particularly serious when it strikes at these infrastructural elements; and, for those communities that increasingly transact and interact online, this is an extremely serious matter. ${ }^{63}$ Nevertheless, this is not part of the generic infrastructure. Having said that, it is much less clear how we should distinguish between infrastructures and activities that take place on those infrastructures. An agent's basic health and well-being can be harmed by the isolated act of another human, by some inhibiting situational threat (such as that of terrorism), or by deficient living conditions. What makes a feature generically infrastructural is that it strikes at the general possibility of agency, irrespective of the agent and of an agent's particular purposes, rather than the particular occurrent prospects of the agent. Or, to put this another way, there first has to be infrastructure and then there can be activity: while there can be infrastructure without activity, there can be no activity without infrastructure.

If we think about the regulatory environment in this kind of way, we can begin to distinguish between those parts of the environment that are designed to secure the infrastructural conditions and those parts that are intended to direct the conduct of regulatees as they act, transact and interact on the infrastructure. Inevitably, there will be cases that are clearer than others: for example, it is clear that, while deficient living conditions are infrastructural, an isolated assault is not; and, depending on the scale and intensity of the threat, we might find it more difficult to classify terrorism. At all events, it is arguable that four major regulatory implications follow from this.

First, while the former part of the regulatory environment should apply to securing the generic infrastructure for agency itself, the latter (the regulation of agents' on-stage interactions and transactions) can be more tuned to local cultural commitments and preferences. To put this in cosmopolitan terms, while all regulators share a responsibility for securing the essential infrastructural conditions, within each community of rights there is room for some (legitimate) variation in the regulation of local activities. ${ }^{64}$

Secondly, if the infrastructure is to be secured, this implies a considerable degree of international co-ordination and shared responsibility. Moreover, because politics tends to operate with short-term horizons, it also implies that the regulatory stewards have some independence from the political branch.

Thirdly, as I have indicated in the previous part of the paper, a form of pure precautionary reasoning might be acceptable in defence of the infrastructure. ${ }^{65}$ According to such reasoning, where the regulatory stewards cannot rule out the possibility that some activity threatens the infrastructure, then they may in good faith apply protective measures even though such measures involve some sacrifice of a valued activity. This reasoning, it should be emphasised, assumes an active employment of precaution. It is not simply that a

63 Following the devastating DDoS (distributed denial of service) attacks on Estonia in 2007, the question of the vulnerability of critical information infrastructures in Europe rapidly moved up the political agenda: see, House of Lords European Union Committee, Protecting Europe Against Large-Scale Cyber-Attacks (Fifth Report, Session 2009-2010).

64 For further discussion, see R Brownsword, "Regulatory cosmopolitanism: clubs, commons, and questions of coherence", TILT Working Papers, No 018/2010 (University of Tilburg 2010).

65 Cf. D Beyleveld and R Brownsword, "Complex technology, complex calculations: uses and abuses of precautionary reasoning in law" in Düwell and Sollie (eds), Evaluating New Technologies, n. 16 above, p. 175. 
lack of full scientific certainty is no reason (or excuse) for inaction - rather, where the harm concerns the infrastructure, there is a need to initiate preventive and protective action. ${ }^{66}$

Fourthly, for communities that have moral aspirations or that value their individual autonomy, it is important that the regulatory environment does not design out the opportunities for acting freely or doing the right thing. Nevertheless, where the regulatory stewards are acting to protect the infrastructure, a resort to designed-in solutions may be more readily justified.

Let us think about how this might play in the context of public health biobanking, for which many societies now have a passion. According to the Ethics and Governance Framework, version 3.0 (October 2007) for UK Biobank, ${ }^{67}$ the Biobank

... will serve as the steward of the resource, maintaining and building it for the public good in accordance with its purpose. This implies both the judicious protecting and sharing of the resource. It also extends to the careful management of any transfer of parts or all of the database or sample collection.

Given that the purpose of projects such as UK Biobank is to improve our understanding of the interactions between genetic profiles, physical environments and lifestyles, and their impact on the health of individuals (as well as the health of larger populations), how does stewardship (with an infrastructural focus) fit in? Do we see any resulting improvement in our understanding as relating to the generic infrastructure or simply to agents' activities on an already secured infrastructure? Do we understand more about how to set the stage (the infrastructure), or is it the performance (the activity) that we understand how to improve? For, to the extent that it is infrastructural, the stewardship jurisdiction may be invoked with all that this entails for the character of the regulatory environment. However, we need to be careful - and nowhere more so than in a community of rights, where agents value the opportunity to choose their own lifestyle. Even if there is a public health concern about, let us say, obesity, as Inez de Beaufort has provocatively asked, why shouldn't those who have a sweet tooth carry on eating "queen of puddings, sticky toffee puddings, and knickerbocker glories"?68

In the light of these remarks, imagine that, 50 years from now, Biobank research has yielded important findings about the causes of major diseases. Equipped with this understanding, the state is in a position to make effective interventions that will reduce the incidence of disease. What would the community make of the following kinds of publichealth directed measures that are proposed by the state? First, with a range of key genetic markers now identified, and with techniques such as pre-implantation genetic diagnosis now wholly reliable and sophisticated, what if the state proposes that any embryos that carry a relevant marker should not be used? We should recall that such screening already takes place for markers associated with a predisposition to cancer; so why not also for markers associated with, say, obesity or addiction? Or, what if a similar approach is taken to pre-natal testing, so that a fetus with the relevant marker is recommended for abortion (or is required to be aborted)? Secondly, what if products (such as tobacco and alcohol) that are judged to be contrary to public health are prohibited? Or, again, what if certain lifestyles are treated in the same way? Thirdly, what if the physical environment is designed in ways that are not

66 Cf. E Fisher, J Jones and R von Schomberg, "Implementing the precautionary principle: perspectives and prospects" in Fisher et al., Implementing the Precautionary Principle, n. 54 above; and E Fisher, Risk Regulation and Administrative Constitutionalism (Oxford: Hart 2007).

67 www.ukbiobank.ac.uk/docs/EGF20082.pdf.

68 Whose Potbelly Is It Anyway? public lecture, hosted by the Nuffield Council on Bioethics, delivered at the Royal Society, London, 26 April 2010. 
simply conducive to health but that present agents with no option other than the healthy one? What if the only way to get from A to B is to walk or to use the stairs? In short, how far, in a community of rights, will it be accepted that the state as steward for public health can not only set the stage in the right (health-promoting) way but may also act as gatekeeper for who is admitted to the community and then as a monitor of individual lifestyles? ${ }^{69}$

These are difficult questions. However, we should not despair. If a community of rights can (and should) debate questions concerning the regulation of activities (of acts, interactions and transactions), so it can (and should) debate its best understanding of the distinction between infrastructure and activity - and, concomitantly, its understanding of the regulatory competence that follows from this distinction. Of course, whilst there is some comfort in these remarks, we should not be complacent: it is no use initiating such a debate in 50 years' time; this is a debate that must start now.

\section{(ii) THE CONDITIONS FOR MORAL COMMUNITY}

Just as there is a generic infrastructure for agency simpliciter (irrespective of whether agents are moralists or amoral prudentialists), so there are generic conditions for the moral life (for all moral agents, irrespective of their particular moral credos). In both cases, regulators have super-stewardship responsibilities.

The generic conditions for moral life obtain irrespective of particular substantive moral codes. In other words, these are the conditions that all moralists, whether utilitarian, Kantian, Gewirthian, Rawlsian, or whatever, would agree to be essential for there to be the possibility of moral community and personal moral development. If, as I assume, one of these conditions is that there must be the possibility of individuals acting in a morally guided way, doing the right thing for the right reason, then this bears on the way that regulators regulate. Each moral community, with its own criteria of right action, will have its own view about the legitimacy of particular regulatory standards and purposes; but the communities will be united in agreeing that regulators should not displace moral signals in a way that distorts the regulatory environment. Where prudential signals displace moral signals, it remains possible for regulatees to do the right thing for the right reason - it is just that the moral signal is no longer in the foreground. However, when normative signals are displaced by non-normative signals of practicability and possibility, regulatees can find themselves in a position where the only thing that they can do is the right thing - or, at any rate, the thing that the regulators have approved by their design.

There is a great deal of work to be done in clarifying, both as a matter of principle and as matter of practice, how far moral communities can afford the moral signals to fade in their regulatory environments. I have said already that it might be legitimate to rely on design in order to protect the essential infrastructure. However, this is exceptional and the real question is about the legitimacy and effect of using a technical fix in relation to a routine activity. Unless we categorically rule out the use of design as a regulatory strategy, the default position seems to be that such a regulatory strategy is legitimate unless it goes beyond a point (possibly a tipping point) at which the opportunity for moral development is lost. However, this gives little specific guidance. How might we begin to specify the ground rules for responsible regulation in this context? For example, is it responsible (and legitimate) to resort to design when this is a safety feature that is intended to reduce defective implementation (unintentional harm) rather than acts of intentional harm? Or, should it be acts of intentional harm that are the first priority for a technical fix? Then, 
does it matter whether the design is in products, places or people? These are all challenging questions. ${ }^{70}$

Even if we can draft some guiding principles for the appropriate use of the nonnormative regulatory register, there is still the question of how, in practice, regulators can be kept in line. Given that politicians are likely to be tempted to deploy regulatory strategies that "work", there will need to be independent procedures for review. Accordingly, within each aspirant moral community, there will need to be local procedures to hold regulators to account, and to challenge particular interventions, whenever regulatory reliance on design departs from guiding principles or raises questions about the sustainability of moral community.

\section{Conclusion}

In this paper, I have referred from time to time to questions of health and I should conclude with a large health warning. In Rights, Regulation and the Technological Revolution, I said that, even such a long book did little more than scratch the surface, that in all areas there was unfinished business. Having been gently chided for entering such caveats, I hesitate to repeat them. ${ }^{71}$ Nevertheless, although I have tried to take things forward in this present essay, I am all too aware that, with each elaboration, further questions arise. For example, the idea of the regulatory environment has no obvious limits. Where does it start and where, precisely, does it finish? In what circumstances and for what purposes is it permissible to rely on non-normative regulatory strategies? The line between prudential and moral reasoning is tricky (particularly where prudential preference maximisation merges into a regulatory script for utilitarian reasoning). The idea of pure precautionary reasoning (let alone moral precautionary reasoning) ${ }^{72}$ invites much further analysis, as does the concept of the essential infrastructure upon which it draws. Stewardship, whether super or standard, needs to be handled very carefully and, in some cases, it might seem like a hostage to fortune. ${ }^{73}$ Is it responsible to embrace such an idea, to contemplate such a regulatory jurisdiction?

We should also remember that, although responsible regulation might start with safety concerns, it certainly does not end there. As Maria Lee ${ }^{74}$ has observed:

The proper regulation of controversial technologies ... is complex and contested. Difficult questions about the safety of these technologies, for the environment and for human health, resonate at the highest political level. There is also however another politics of regulation: whilst environmental and human safety are important, complex and political, so may be, for example, the way a

70 The best place to start thinking about these issues is K Yeung, "Towards an understanding of regulation by design" in R Brownsword and K Yeung (eds), Regulating Technologies (Oxford: Hart 2008), p. 79. For more recent reflections, see K Yeung, "Can we employ design-based regulation while avoiding Brave New World" (2011) 3 Law, Innovation and Technology 1; and R Brownsword, "Lost in translation: legality, regulatory margins, and technological management" (2011) 25 Berkeley Technology Law Journal (forthcoming).

71 See D Morgan, "Technology in the age of anxiety: the moral economy of regulation" (2009) 29 Legal Studies 492 , which sparks off so many thoughts that it succeeds only in persuading me that the caveats were undoubtedly required.

72 Compare the idea of "procautionary" reasoning in R Brownsword, "Nanoethics: old wine, new bottles?" (2009) 32 European Journal of Consumer Policy 355.

73 In this respect, we should note Han Somsen's cautionary remarks: see, H Somsen, "Cloning Trojan Horses: precautionary regulation of reproductive technologies" in Brownsword and Yeung (eds), Regulating Technologies, n. 70 above, p. 221.

74 M Lee, "Beyond safety? The broadening scope of risk regulation" (2009) 62 Current Legal Problems 242. 
technology distributes risk and benefit; the social and political arrangements a technology might favour; and the real purposes of the technology. ${ }^{75}$

Beyond the politics of risk regulation, there are, indeed, difficult questions of equity and ethics that remind us that responsible regulators will aspire to set legitimate standards as well as to set about the regulatory enterprise in the right kind of way. So, this really is work in progress. Moreover, with the constant acceleration in emerging technologies, coupled with changing social attitudes, this is in all probability how the work, both practical and theoretical, is destined to remain. ${ }^{76}$

75 Lee, "Beyond safety?", n. 74 above, p. 243.

76 O Bekou and T Murphy surely put their finger on it when they remark in a recent editorial introduction to a special issue on human rights and new technologies that "negotiating the mix of hope, hype, fear and quotidian use that surrounds new technologies is not going to be easy - either for individuals or groups, or indeed for regulators": see (2010) 10 Human Rights Law Review 597. For earlier reflections on the relationship between human rights and new technologies, see T Murphy (ed.), New Technologies and Human Rights (Oxford: OUP 2009) and "Technology, tools, and toxic expectations: post-publication notes on New Technologies and Human Rights" (2009) 1 Law, Innovation and Technology 181. 
